\title{
Hepatitis B antigen and antibody in maternal blood, cord blood, and amniotic fluid
}

\author{
G. PAPAEVANGELOU, T. KREMASTINOU, C. PREVEDOURAKIS, and D. KASKARELIS \\ From the Department of Hygiene and Epidemiology and the 2nd Obstetrical and Gynaecological Clinic of the \\ University of Athens
}

\begin{abstract}
Papaevangelou, G., Kremastinou, T., Prevedourakis, C., and Kaskarelis, D. (1974). Archives of Disease in Childhood, 49, 936. Hepatitis $B$ antigen and antibody in maternal blood, cord blood, and amniotic fluid. Transplacental transmission of hepatitis B virus from hepatitis B antigen carrier mothers was investigated by studying the presence of the antigen and its antibody in maternal blood, umbilical cord blood, and amniotic fluid. Hepatitis B antigen was shown in the umbilical cord blood of 2 out of 14 newborns whose mothers were permanent hepatitis $B$ antigen carriers. The antigen was eliminated from the blood of these newborns in less than 3 months. It was also detected in the concentrated amniotic fluid of one hepatitis B antigen cord blood-positive case. Antibodies (anti-HBs) crossed the placental barrier easily and were found in the umbilical cord blood and in the amniotic fluid. They were not detected in the umbilical cord blood and amniotic fluid of any of the studied newborns of hepatitis B antigen carrier mothers.

These data indicate that the fetuses of carrier mothers are exposed to the hepatitis B virus. However, chronic antigen positivity and anti-HBs production was not shown. Occurrence of in utero infection and subsequent resolution cannot be excluded, but it appears more probable that in utero infection is blocked.
\end{abstract}

Conflicting reports have been published recently regarding transplacental and neonatal transmission of hepatitis B virus from hepatitis B antigen carrier mothers (London, Difiglia, and Rodgers, 1969; Schweitzer et al., 1972; Alexiou et al., 1972). Maternal-neonatal transmission would be shown if infection of the infant were manifested by clinical disease, antigen positivity, or anti-HBs production. This investigation extends previous studies of transmission of hepatitis B virus from carrier mothers to their newborns (Alexiou et al., 1972, 1973), and includes hepatitis $B$ antigen and antiHBs studies in the maternal blood, umbilical cord blood, and amniotic fluid.

\section{Material and methods}

Between December 1970 and October 1973 a random sample of 428 women entering the Obstetric Clinics of the University of Athens were included in the present study. Maternal and umbilical cord bloods were drawn aseptically and the serum was stored at $-60{ }^{\circ} \mathrm{C}$ until tested. In 69 of them amniotic fluid was drawn at the

Reccived 19 April 1974 time of delivery, concentrated 10 times, and stored at $-60{ }^{\circ} \mathrm{C}$.

Hepatitis B antigen was detected by counter-immunoelectrophoresis in $14(3.3 \%)$ mothers. 2 of them were not included in the present study because cord blood was not available. 2 of the positive mothers gave birth to another baby 24 and 30 months after their first deliveries. Thus, the study included 12 positive mothers and their 14 newborns.

None of the antigen-positive mothers had overt signs of liver disease during the pregnancy or at delivery. They were re-examined at 3 and 6 months after delivery; all remained antigen positive. Though liver biopsy was not performed, the absence of substantial biochemical abnormalities (intermittent rise in SGPT values to as high as 100 Karmen units), and the permanency of the carrier state, indicated that they were asymptomatic carriers and not subclinical infections.

Hepatitis $B$ antigen testing. All mothers were screened for antigen by counter-immunoelectrophoresis (Pesendorfer, Krassnitzky, and Wewalka, 1970). The solid phase radioimmunoassay ${ }^{\star}$ was used to extend the

^Ausria, Abbot Laboratories. 
sensitivity of antigen testing in the umbilical cord and amniotic fluid of antigen-positive mothers (Aach, Grisham, and Parker, 1971).

Anti-HBs testing. 173 mothers were screened for anti-HBs by the passive haemagglutination assay (Vyas and Shulman, 1970). Red cells coated with purified hepatitis B antigen were purchased from Electro-

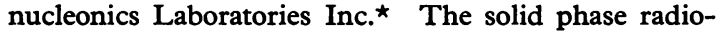
immunoassay for the detection of anti-HBst was used for anti-HBs determination in the cord blood and amniotic fluid of antigen-positive or anti-HBs- (as determined by passive haemagglutination assay) positive mothers.

\section{Results}

Hepatitis B antigen. This was not detected in the umbilical cord blood of the antigen-negative mothers. It was shown by radioimmunoassay in the umbilical cord of 2 out of the 14 newborns, whose mothers were permanent antigen carriers. In one of them the antigen was shown in the cord blood by counter-immunoelectrophoresis, too. In this case it was also shown in the concentrated amniotic fluid by radioimmunoassay. It was not shown in the amniotic fluid of another newborn whose mother was a carrier. In that case the antigen was also absent from the umbilical cord blood. Amniotic fluids from the other 10 antigenpositive cases were not available. The antigen was not shown in blood samples drawn at 3 months after delivery from infants of carrier mothers. It was also eliminated from the 2 infants whose cord blood was antigen-positive.

Anti-HBs. Anti-HBs were not detected in the maternal blood, umbilical cord blood, and amniotic fluid of any one of the studied hepatitis B antigenpositive cases. Anti-HBs studies were performed in 161 antigen-negative pairs of maternal and cord blood. Table I shows that anti-HBs were absent from the umbilical cord of 1 out of the 38 anti-HBspositive mothers. In that case the anti-HBs titre of the mother was 1:8. The Fig. shows that a correlation existed between maternal and umbilical cord blood anti-HBs titres $(r=0 \cdot 7, P<0 \cdot 01)$. Anti-HBs titres tended to be lower in the umbilical cord blood than in maternal blood.

Amniotic fluid was available from 10 anti-HBspositive mothers as well as from 59 negatives. Anti-HBs were not found in the amniotic fluid of the negative mothers and in 3 out of the 10 positives. In Table II the anti-HBs titres in maternal blood, cord blood, and amniotic fluid of the 10 anti-HBs-

*Virgo Reagents, Maryland, USA.

†Ausab, Abbot Laboratories.
TABLE I

Antibody to hepatitis $B$ antigen (anti-HBs) in the umbilical cord blood according to anti-HBs status of mother at delivery

\begin{tabular}{|c|c|c|c|}
\hline \multirow{2}{*}{$\begin{array}{c}\text { Maternal } \\
\text { blood }\end{array}$} & \multicolumn{3}{|c|}{ Umbilical cord blood } \\
\hline & Positive & Negative & Total \\
\hline $\begin{array}{l}\text { Positive } \\
\text { Negative }\end{array}$ & 37 & $\begin{array}{r}1 \\
123\end{array}$ & $\begin{array}{r}38 \\
123\end{array}$ \\
\hline Total & 37 & 124 & 161 \\
\hline
\end{tabular}

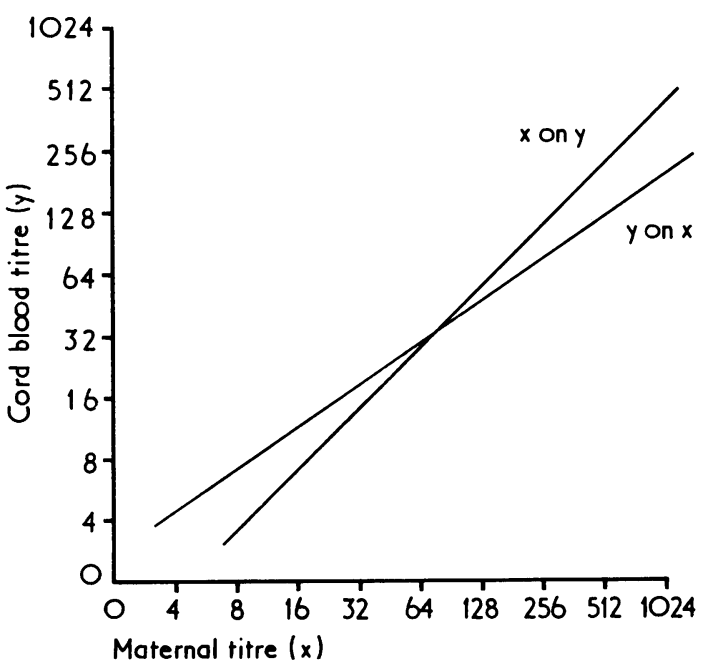

Fig.-Correlation between maternal and umbilical cord blood antibody titres to hepatitis $B$ antigen.

TABLE II

Comparison of antibody to hepatitis $B$ antigen (anti-HBs) titres* in maternal blood, cord blood, and amniotic fluid

\begin{tabular}{c|r|r|r}
\hline Case no. & $\begin{array}{c}\text { Maternal } \\
\text { blood }\end{array}$ & Cord blood & $\begin{array}{c}\text { Amniotic } \\
\text { fluidt }\end{array}$ \\
\hline 1 & 256 & 256 & 256 \\
2 & 512 & 256 & 8 \\
3 & 256 & 256 & 16 \\
4 & 1.024 & 1.024 & 16 \\
5 & 256 & 64 & 16 \\
6 & 1.024 & 256 & - \\
7 & 8 & 512 & - \\
8 & 32 & $\overline{64}$ & - \\
9 & 8 & 73 & 32 \\
10 & 128 & & 12 \\
\hline G.M.T. & 141 & & \\
\hline
\end{tabular}

*Reciprocal of the highest dilution giving complete haemagglutination.

†Tested by passive haemagglutination assay after $10 \times$ concentration. 
positive cases are compared. Anti-HBs titres were significantly lower in the concentrated amniotic fluid than in maternal (paired ' $t$ ' test $=3 \cdot 8, \mathrm{P}<0 \cdot 01$ ) or cord blood $(t=3,1, P<0 \cdot 05)$. No correlation existed between cord blood and amniotic fluid anti-HBs titres $(P>0 \cdot 1)$.

\section{Discussion}

In recent studies the use of less sensitive methods failed to prove unequivocally the placental transmission of hepatitis $B$ antigen (London et al., 1969; Alexiou et al., 1972; Aziz et al., 1973). Our data, as well as those of other studies, indicate that transplacental transmission of the antigen from asymptomatic carriers is not uncommon (Keys et al., 1971; Schweitzer et al., 1972). It is likely that an even higher incidence of transmission would have been found if a more sensitive technique were available. Our results also show that when a higher level of viraemia exists in cord blood (detection of antigen by counter-immunoelectrophoresis), the antigen may be found in the amniotic fluid. Thus, the transplacental transmission of the hepatitis $B$ antigen need not be attributed to mechanical damage or to altered permeability of the placental barrier, since it is perhaps a regular phenomenon.

Our studies indicate that the fetuses of carrier mothers are exposed to the hepatitis B virus, to the extent that the virions are responsible for the antigen reaction. Subsequent infection of the infant would be suggested if neonatal hepatitis, antigen positivity, production of anti-HBs, or subsequent immunity of the infant on exposure could be shown.

A high incidence of neonatal infection occurs as a result of acute maternal hepatitis $\mathrm{B}$, especially in the third trimester of pregnancy or in the immediate post-partum period (Turner et al., 1971; Wright et al., 1970; Cossart, Hargreaves, and March, 1972; Schweitzer et al., 1973). With the carrier state on the other hand, neonatal hepatitis seems not to occur (Skinhøj et al., 1972; Alexiou et al., 1972). Schweitzer et al. (1973) suggested that infection of the fetus may be blocked or resolved when it occurred early in gestation because of transfer of some maternal factor (antibody or interferon). Against this is the report of 4 cases of hepatitis in neonates of carrier mothers (Gillespie et al., 1970; Charalambidis and Hadjiyannis, 1971; Keys et al., 1971; Schweitzer et al., 1973), but in these cases it was not established that the carrier state antedated pregnancy or that it was not initiated by a subclinical infection late in pregnancy. In our series all mothers were permanent asymptomatic carriers and in at least 2 of them the carrier state antedated pregnancy.

In the present study it was shown, as expected, that anti-HBs easily cross the placental barrier and may be present in a relatively low level in the amniotic fluid. Anti-HBs were not detected in the cord blood of the 14 babies studied who were born to carrier mothers. This may be attributed to the blocking of infection of the fetus (Schweitzer $e t$ al., 1973) or to immune tolerance. However, the possibility of in utero infection and production of very low levels of anti-HBs, because of the relative immaturity of the immune system of the fetus, cannot be excluded. Such low levels of anti-HBs may not be detected by the presently available methods. Nevertheless, they may help the newborn to eliminate the hepatitis $\mathrm{B}$ antigen and protect the infant from reinfection and clinical disease. This may explain the loss of the antigen positivity from the cord blood positive cases when they were retested 3 months later. It may also explain the prompt elimination of the antigen when infants born to carrier mothers were subclinically infected some months after delivery (Alexiou et al., 1973, Papaevangelou, 1973).

Transmission of hepatitis B virus from mother to infant at the time of birth seems not to be the basis of both acquisition and persistence of hepatitis $B$ antigen in asymptomatic carriers, as suggested by Merrill, Dubois, and Kohler (1972). As already mentioned, persistent antigenaemia rarely develops in infants born to carrier mothers (Papaevangelou, 1973).

There are no data on the immunity of these infants on later exposure. Anti-HBs and antibody to hepatitis B cord antigen follow-up studies of these children may provide further answers, and such studies are now in progress.

\section{REFERENCES}

Aach, R. D., Grisham, J. W., and Parker, C. W. (1971). Detection of Australia antigen by radioimmunoassay. Proceedings of the National Academy of Sciences of the U.S.A., 68, 1056.

Alexiou, D., Papaevangelou, G., Papadatos, C., Georgiopoulos, F., and Kremastinou, T. (1972). Transmission of the antigen related to viral hepatitis (Australia antigen) to the foetus and to the neonate. Archives of the Hellenic Pédiatric Association, 35, 1.

Alexiou, D., Papaevangelou, G., Papadatos, C., Georgiopoulos, F., and Courea-Cremastinou, T. (1973). Australiémie chronique asymptomatique et grossesse. Pediatrie, XXVII, 733.

Aziz, M. A., Khan, G., Khanum, T., and Siddiqui, A. (1973). Transplacental and postnatal transmission of the hepatitisassociated antigen. fournal of Infectious Diseases, 127, 110.

Charalambidis, B., and Hadjiyannis, S. (1971). Viral hepatitis with Au antigen in an infant. 2nd Panel Congress of Gastroenterology, 13-16 October, Athens.

Cossart, Y. E., Hargreaves, F. D., and March, S. P. (1972). Australia antigen and the human fetus. American fournal of Diseases of Children, 123, 376. 
Gillespie, A., Dorman, D., Walker-Smith, J. A., and Yu, J. S. (1970). Neonatal hepatitis and Australia antigen. Lancet, 2, 1081.

Keys, T. F., Hobel, C. J., Oh, W., Gitnick, G. L., and Hewitt, W. L. (1971). Maternal and neonatal Australia antigen. Clinical Rerearch, 19, 184.

London, W. T., Difiglia, M., and Rodgers, J. (1969). Failure of transplacental transmission of Australia antigen. Lancet, 2, 900.

Merrill, D. A., Dubois, R. S., and Kohler, P. F. (1972). Neonatal onset of the hepatitis-associated-antigen carrier state. New England fournal of Medicine, 287, 1280.

Papaevangelou, G. J. (1973). Hepatitis B in infants. New England Fournal of Medicine, 288, 972.

Pesendorfer, F., Krassnitzky, O., and Wewalka, F. (1970). Immunoelektrophoretischer Nachweis von HepatitisAssociated-Antigen (Au-SH-Antigen). Klinische Wochenschrift, 48, 58 .

Schweitzer, I. L., Mosley, J. W., Ashcavai, M., Edwards, V. M., and Overby, L. B. (1973). Factors influencing neonatal infection by hepatitis B virus. Gastroenterology, 65, 277.
Schweitzer, I. L., Wing, A., McPeak, C., and Spears, R. L. (1972). Hepatitis and hepatitis-associated antigen in 56 mother-infant pairs. Fournal of the American Medical Association, 220, 1092.

Skinhøj, P., Olesen, H., Cohn, J., and Mikkelsen, M. (1972). Hepatitis-associated antigen in pregnant women. Acta Pathologica et Microbiologica Scandinavica, Section B, 80, 362.

Turner, G. C., Field, A. M., Lasheen, R. M., Todd, R. McL., White, G. B. B., and Porter, A. A. (1971). SH (Australia) antigen in early life. Archives of Disease in Childhood, 46, 616.

Vyas, G. N., and Shulman, N. R. (1970). Hemagglutination assay for antigen and antibody associated with viral hepatitis. Science, 170, 332.

Wright, R., Perkins, J. R., Bower, B. D., and Jerrome, D. W. (1970). Cirrhosis associated with the Australia antigen in an infant who acquired hepatitis from her mother. British Medical fournal, 4, 719.

Correspondence to Dr. G. Papaevangelou, 52 Skoufa Street, Athens 135, Greece.

The following articles will appear in future issues of this journal:

Current topics: The community paediatrician in an integrated child health service. J. A. Davis and F. N. Bamford.

Thyroid function during exchange transfusion. R. D. G. Milner and J. G. Ratcliffe.

Rickets in Tehran: study of 200 cases. $R$. Salimpour.

Familial hyperargininaemia. H. G. Terheggen, A. Lowenthal, F. Lavinha, and J. P. Colombo.

Immunodeficiency and infantile bone and joint infection. K. N. Kuo, G. C. Lloyd-Roberts, I. M. Orme, and J. F. Soothill.

Follicular ovarian cysts in stillbirths and neonates. D. J. deSa.

Prediction of adult height from height, bone age, and occurrence of menarche, at ages 4 to 16 with allowance for midparent height. J. M. Tanner, R. H. Whitehouse, W. A. Marshall, ana B. S. Carter.

Unusual clinical course in a child with cystic fibrosis treated with fat emulsion. $R$. B. Elliott and P. G. Robinson.

Early life of the 'battered child'. R. R. Holman and S. Kanwar. 